\title{
PARADIGMAS CONTEMPORÂNEOS E A EDUCAÇÃO SUPERIOR
}

\author{
Prof. ${ }^{\text {a }}$ Ester Framarin de S. SILVA* \\ Prof. a Gisele Pontaroli RAYMUNDO** \\ Prof.. ${ }^{\text {a }}$ Dr. ${ }^{\text {a }}$ Marilda Aparecida BEHRENS***
}

\section{Resumo}

O presente artigo tem como finalidade provocar os docentes universitários no sentido de refletir sobre as mudanças necessárias na Educação Superior em face às transformações sociais da atualidade. Mudar a maneira de ver e agir requer de nós, docentes, conscientização, leitura, pesquisa e reflexão no que diz respeito aos paradigmas educacionais conservadores e emergentes.

Palavras-chave: Educação - Mudança - Paradigmas - Docência.

\section{Abstract}

The purpose of this paper is to rouse among the university professors a reflection about the inevitable changes on the undergraduate teaching because of the present social transformations. Changing the way of seeing and acting about that, require from us, professors, consciousness, reading, research and reflection about the traditional and emergent educational paradigms.

Keywords: Education - Change - Paradigms - Teaching.

\section{Introdução}

O desafio de investigar a prática pedagógica leva alguns docentes a buscar o Mestrado em Educação, em especial, o da Pontifícia Universidade Católica do Paraná, porque tem como objeto principal a pesquisa do pensamento Pedagógico Brasileiro e a Formação de Professores. As inquietações dos mestrandos se afloram ao freqüentar as disciplinas, pois no momento em

* Mestranda em Educação pelo Programa de Pós-Graduação da PUCPR, Coordenadora e professora de Língua Inglesa do Curso de Letras Português/Inglês das Faculdades FACEL.

* Mestranda em Educação pelo Programa de Pós-Graduação da PUCPR, Graduada em Nutrição e Professora dos Cursos de Nutrição da UnicenP e Uniandrade.

*** Mestre e Doutora em Educação. Professora/Pesquisadora do Mestrado em Educação da PUCPR. educacao@rla13.pucpr.br 
que passam a conviver com os professores de diversas áreas do conhecimento, estes os instigam a repensar seus posicionamentos sobre a prática enquanto profissional da docência.

O objeto central da proposta do Mestrado é tornar o professor um pesquisador de sua própria prática pedagógica. As disciplinas ofertadas e os seminários avançados de pesquisa provocam no mestrando uma reflexão sobre seu papel enquanto profissional, pesquisador e docente. Com a clareza de que todas as disciplinas cursadas são relevantes, focalizar-se-á neste artigo a disciplina de Paradigmas Contemporâneos na Educação Superior, na qual é colocado o desafio de refletir sobre as questões inerentes à docência, especialmente, a partir das perguntas de pesquisa:

Se a maioria dos professores só ensina a copiar, decorar e repetir, como se estruturará uma mudança criativa, crítica e transformadora nos meios acadêmicos? Como oferecer aos professores universitários subsídios para produzirem referenciais sobre os paradigmas pedagógicos inovadores na prática educativa? Quais os referenciais que caracterizam o paradigma emergente na prática pedagógica do professor da Educação Superior?

A problemática levantada passa a ser desafiadora no momento em que se propõe uma discussão coletiva com os mestrandos para encontrar caminhos que levem a algumas respostas possíveis, na certeza de que também estas serão provisórias.

A exigência legal de desenvolver "Estágio Docente" para Bolsistas do CNPq leva os mestrandos envolvidos a produzirem este texto. A partir da oportunidade de acompanhar o professor da disciplina, passam a discutir a viabilidade de refletir sobre novos caminhos na docência e compartilhar suas vivências, produzindo conhecimento sobre a temática proposta.

\section{Ocaminhopercorrido na reflexão docente}

Se fôssemos procurar um significado para MESTRADO, com certeza, todas as palavras existentes em nosso idioma não seriam suficientes para traduzir o que acontece conosco durante este período. Talvez a que mais se aproxime do verdadeiro sentido seja: REFLEXÃ̃O. É o momento em que paramos para pensar com maturidade sobre a nossa prática pedagógica em relação aos nossos alunos, às instituições e, principalmente, com relação à visão de mundo. Este retroceder "momentâneo" é uma volta à consciência, a um repensar sobre nós mesmos, oportunizando uma investigação do nosso próprio conhecimento por meio do entendimento do papel que desempenhamos enquanto pessoa, docente e profissional.

O ponto essencial das discussões, entre os professores - mestrandos que se envolvem na disciplina de Paradigmas Contemporâneos na Educação 
Superior, é a visão de que a Educação, entre tantas áreas do conhecimento, busca nas últimas décadas a superação dos paradigmas conservadores na prática pedagógica. Em especial, a necessidade de ultrapassar os processos educativos que envolvem a cópia, a fragmentação do conhecimento e a visão acrítica dos alunos. O processo de transformação requer do docente uma conscientização a respeito das necessidades de mudanças. Muita leitura, troca de experiências, diálogo crítico e pesquisa são os requisitos importantes na preparação do professor para enfrentar esta nova realidade. A partir destas reflexões é que nos propusemos a escrever este artigo.

\section{Aproblemática levantada ex igea definição sobreparadigmas}

A compreensão da mudança de um paradigma para outro passa pelo entendimento do que vem a ser um paradigma. Para KUHN (1998) "paradigma significa a constelação de crenças, valores e técnicas partilhadas pelos membros de uma comunidade científica" (p. 225). Segundo MORIN (1996) "um paradigma é um tipo de relação muito forte, que pode ser de conjunção ou disjunção, que possui uma natureza lógica entre um conjunto de conceitos-mestres" (p. 287). CARDOSO (1995) propõe que "o conceito de paradigma é entendido como um modelo de pensar e ser capaz de engendrar determinadas teorias e linhas de pensamento dando certa homogeneidade e um modo de o homem ser no mundo, nos diversos momentos históricos" (p. 17).

O estudo do fenômeno paradigmático, feito por estes e muitos outros autores, leva-nos a entender que o homem é o elemento articulador da construção do universo. O mundo caminha de acordo com os modelos de ciência que o homem cria e recria.

A mudança pela qual estamos passando não invalida o paradigma newtoniano-cartesiano que vem caracterizando a ciência nos dois últimos séculos, pois os conhecimentos que foram produzidos não devem ser anulados e sim transformados em benefício da humanidade. Hoje os questionamentos gerados pelas mudanças na história da humanidade não são mais respondidos pelo paradigma anterior e, portanto, necessitam de novos pressupostos, visões e encaminhamentos. Esta fase de transformação paradigmática pela qual o homem está passando é constituída por rupturas em todos os âmbitos: sociais, políticos, ecológicos, religiosos, econômicos e, em particular, os educacionais.

\section{Atransição paradigmática na sociedade}

O século XX, em sua grande parte, caracterizou-se por uma "Socieda- 
de de Produção em Massa", assentada nos pressupostos do paradigma newtoniano-cartesiano. Essa visão paradigmática levou o homem e a sociedade a serem vistos de forma fragmentada, tendo como foco a reprodução do conhecimento. Neste contexto, observamos que a Educação funcionava como um mundo à parte da sociedade, que era fechada e protegida pelos paradigmas conservadores. Os processos pedagógicos eram restritos a ações que envolviam o "escute, leia, decore e repita" (BEHRENS, 1999, p. 45). O desafio de superar a visão conservadora, portanto, o paradigma newtoniano-cartesiano, levou WEIL (IN: BRANDÃO \& CREMA,1991) a propor a relevante reflexão:

Nosso mundo está em crise, provocada por lacunas e falhas do paradigma reinante e suas extrapolações. A felicidade prometida pelas aplicações indiscriminadas da ciência moderna, sob forma de tecnologia está se transformando no seu contránio; de um lado, temos a falta elementar de alimento e conforto, que traz fome e miséria física ao Terceiro Mundo, do outro lado, temos a miséria psicológica que acompanha o excesso de alimento e conforto dos países desenvolvidos, onde cresce a solidão, a indiferença, a violência sob todas as formas; o confronto não trouxe felicidade, qualquer que seja o regime reinante (p. 16).

No início do século XX, acompanhando o paradigma newtonianocartesiano aparece a Revolução Industrial e, nas suas últimas décadas, a Revolução Tecnológica. A tendência de uma visão tecnológica do mundo levou ao desenvolvimento acelerado, no entanto, acirrou o processo de desumanização do homem. Na realidade não se trata de desconsiderar o valor da tecnologia, mas de entendê-la como suporte para instrumentalizar o homem em suas ações e não tratá-la como centro de valor em si mesma. Com essa visão, FREIRE (2001, p. 57) alerta:

A técnica é sempre secundária e só é importante quando a serviço de algo mais amplo. Considerar a técnica primordial é perder o objetivo da educação. A questão não são as técnicas em si mesmas -não que não sejam importantes-, mas a verdadeira questão é a compreensão da substantividade do processo que, por sua vez, requer múltiplas técnicas para atingir um objetivo em particular. É o processo que leva à necessidade das técnicas que precisa ser entendido.

Embora os cientistas proponham a superação do paradigma newtoniano-cartesiano desde o início do século $\mathrm{XX}$, defendendo uma reaproximação das partes e a busca de uma visão de todo, só nas últimas décadas do século XX a educação apresenta um forte movimento de mudança paradigmática. A comunidade científica, os pesquisadores, os educadores e os 
profissionais em geral adentram o século XXI, acompanhados por um inegável avanço tecnológico. Porém, passam a acirrar as denúncias sobre a fragilidade dos pressupostos que caracterizam o pensamento newtoniano-cartesiano. Esse paradigma, não dá mais conta de atender às exigências da Sociedade do Conhecimento e as reais necessidades de transformações sociais. Com esse desafio presente, o homem passa a investigar a ciência buscando novas abordagens que inovem este pensamento. Esse processo de inovação impregna as áreas de conhecimento e leva os pesquisadores a buscar caminhos de superação da visão fragmentada e compartimentalizada de ver o universo.

\section{OsParadigmas Conservadoreseasabordagenseducacionais}

Os paradigmas educacionais conservadores têm como foco essencial a reprodução do conhecimento. A investigação sobre as práticas pedagógicas, propostas ao longo da histónia da educação, apresentam como abordagens conservadoras: a tradicional, a escolanovista e a tecnicista.

Os paradigmas conservadores, que vêm se mantendo ao longo dos séculos, são caracterizados pela prática pedagógica tradicional que enfocam a repetição, a memorização e a reprodução do conhecimento. A abordagem tradicional ainda acompanha a atuação docente de muitos professores em todos os níveis de ensino, em especial, os universitários. Essa abordagem poderia ser descrita, segundo MIZUKAMI (1986), como um processo de conduzir os alunos a um saber erudito, que deveria ser reproduzido para atingir um nível intelectual elevado.

A abordagem escolanovista, proposta por volta de 1930, por educadores do "Movimento da Escola Nova", em especial por Anísio Teixeira, apresenta-se como reação à abordagem tradicional. Essa abordagem aparece como revolucionária para a época e traz uma visão psicológica para a educação. Alguns educadores reagem ao classificá-la como conservadora. No entanto, não podem negar que esta tendência continuava tendo forte influência do paradigma newtoniano-cartesiano. Na entrada do século XX, essa abordagem pedagógica enfatiza o indivíduo e sua ação criadora.Segundo MIZUKAMI (1986)

Essa abordagem dá ênfase a relações interpessoais e ao crescimento que delas resulta, centrado no desenvolvimento da personalidade do indivíduo, em seus processos de construção e organização pessoal da realidade, e em sua capacidade de atuar, como uma pessoa integrada. Dá-se igualmente ênfase à vida psicológica e emocional do indivíduo e à preocupação com a sua orientação interna, com o autoconceito, com o desenvolvimento de uma visão autêntica de si mesmo, orientada para a realidade individual e grupal (p. 38). 
A maior dificuldade de implementar esta proposta educacional foi o despreparo do professor em tomar sobre si a nova atitude e a falta de recursos para implantá-la na escola em todos os níveis. Por conseqüência, o paradigma tradicional continuou a ser proposto dentro da sala de aula.

Por último e dentro dos paradigmas conservadores, surge nos anos setenta a abordagem tecnicista, que propõe uma pedagogia embasada na racionalidade, eficiência e eficácia da produtividade. $O$ foco principal não é 0 sujeito e sim o objeto, provocando a fragmentação do conhecimento entre corpo e mente. De acordo com BEHRENS (1996):

A forte interferência do positivismo e a cisão entre o sujeito e objeto provocam uma educação fragmentada e mecanicista. Ao separar corpo e mente, a ciência transfere para a educação e, por conseqüência, para o ensino um sistema fechado, compartimentalizado e dividido. A ênfase da prática educativa recai na técnica pela técnica. Busca lançar mão de manuais para organizar o processo ensino-aprendizagem (p. 51).

A abordagem tecnicista caracterizou-se pela ênfase na fragmentação do conhecimento, pois fez com que o homem dirigisse seu olhar para uma visão dualista, entre o ter e o ser, a razão e a emoção. Não se pode negar a importância da competência técnica na sociedade moderna. Entretanto, a máquina deve estar a serviço das necessidades humanas e não ao contrário, 0 homem a serviço da máquina.

Torna-se inegável a importância da utilização de recursos tecnológicos que deveria agregar-se às soluções dos problemas gerados pela própria transformação social no sentido de, juntos, o homem instrumentalizado pela máquina, buscar a melhoria da qualidade de vida.

\section{Aproposiçãodonovoparadigma}

O homem e a natureza vêm se transformando com extrema rapidez e, em função disso, a capacidade científica está se tornado cada dia mais relevante. Neste contexto, a Ciência, especialmente a Física Quântica, instiga os pesquisadores a buscarem um novo referencial que dê conta destas transformações. LASZLO (1999) explica este momento como o de reflexão e acrescenta:

Este reexame está sendo feito hoje em dia. Quando os cientistas se deparam com anomalias e paradoxos recorrentes - descobertas e fenômenos que eles não podem explicar - chegam a um ponto além do qual eles não tentam mais remendar suas teorias básicas. Existem tantas exceções e adições aos 
conceitos operativos que ninguém mais sabe como operar com eles. Os insights-chave se obscurecem; o conhecimento trazido por eles se torna questionável (p.125).

Da tentativa de se refletir, explicar e agir diante desse contexto surge um paradigma inovador que se apresenta neste momento histórico com múltiplas denominações. Os autores elegem denominações como: "Ecológico" ou "Sistêmico" (CAPRA, 1996); "Holístico" (BRANDÃO \& CREMA, 1991); e "Paradigma Emergente" (MORAES, 1997 E PIMENTEL, 1993). O que todos têm em comum é a visão de totalidade do mundo e a transposição da reprodução para a produção do conhecimento (BEHRENS, 2000).

O Paradigma Educacional Emergente nasce da preocupação em fundamentar a prática pedagógica às mudanças científicas. Esse paradigma propõe que o universo seja visto como um todo, um sistema integrado, uma concepção de teia e de relações que têm como unidade central a reaproximação das partes, a religação dos saberes (MORIN, 2001) e a união entre sujeito e objeto. Assim, o ensino passa a ser concebido não a partir de uma fragmentação, divisão ou dualidade. Seu eixo principal é a totalidade, no qual o indivíduo faz parte da construção do conhecimento. Este indivíduo não é mais considerado como uma "tábula rasa", onde o papel da escola era o de imprimir como conhecimento verdades absolutas e, portanto, inquestionáveis. A produção do conhecimento significativo exige a superação da visão dualista entre razão e emoção, corpo e mente, ciência e ética, entre outras fragmentações que foram propostas ao longo da história da humanidade.

Neste contexto de mudança cabe salientar que há um sentimento de desconforto diante dos grandes problemas da humanidade, tais como a escassez das necessidades básicas para a sobrevivência de ser humano: água, alimentos, moradia, saúde, emprego. Isto tudo provocado pelo uso descontrolado dos meios naturais e tecnológicos que deveriam servir para aumentar a qualidade de vida do homem. Os profissionais das diversas áreas do conhecimento, pesquisadores, cientistas, professores e a comunidade em geral, neste momento, preocupam-se com o futuro do universo e se unem em comunidades, associações, equipes, escolas, com a intenção de juntos tentar senão resolver, pelo menos atenuar esses problemas, criados pelo próprio homem. A superação da visão cartesiana de conviver no universo tende a abrir espaço para uma atuação ética do homem, enquanto criatura e enquanto cidadão, responsável pela construção de um mundo melhor para a humanidade em geral.

O paradigma emergente enseja a conexão de várias abordagens, visões e entendimentos. A proposição destes paradigmas inovadores leva a exigir a necessidade de inter-relacionamentos de múltiplas teorias que venham dar conta da religação dos saberes (MORIN, 2001) e da visão de todo (CAPRA, 
1996). Alia-se a essas características os pressupostos de totalidade, de relatividade, de processo, de visão de teia, de redes, de sistemas integrados, e de transformação da sociedade. Segundo BEHRENS (1999) o Paradigma Emergente pressupõe a necessidade de interconexão, e para tanto sugere pelo menos três abordagens "a visão holística, a abordagem progressista e o ensino com pesquisa" (p. 60), com o intuito de buscar a produção do conhecimento. Acredita-se que estas abordagens, unidas, poderão ser o alicerce para uma interconexão entre a busca de uma visão de totalidade compatível com as exigências de uma sociedade moderna e suas mudanças científicas.

A visão holística está assentada em uma vida harmoniosa tanto no âmbito pessoal, como no social ou profissional. No campo educacional é preciso que se considere o homem em sua totalidade, com suas inteligências múltiplas, sendo capaz de interagir com ética e sensibilidade. WEIL (In: BRANDÃO \& CREMA, 1991) combina dois enfoques para a compreensão da visão holística:

A holologia que consiste no estudo teórico do antigo e do novo paradigma, das suas conseqüências na vida humana. Ela se estende também à descrição holística, permitindo, no momento oportuno, reconhecer as diferentes vivências como normais para o nível evolutivo alcançado. No início ela permite preparar o intelecto para aceitar e mesmo cooperar para que a vivência holística emerja. E a holopraxis que é o conjunto de métodos que levam à vivência holística ou transpessoal (p. 35).

A visão holística proposta pela GATE (1991) - Global Alliance for Transforming Education, uma organização internacional de cientistas, pesquisadores e professores - oferece ajuda no sentido de propor modificações na visão que permeia o sistema educacional vigente conclamando a todos: "fazemos um chamado a favor de um reconhecimento renovado dos valores humanos que têm sido corroídos pela cultura moderna: harmonia, paz, cooperação, comunidade, honestidade, justiça, igualdade, compaixão, compreensão e amor" (p. 3).

Na abordagem progressista o enfoque está no indivíduo desenvolvendo e compartilhando seu crescimento intelectual por meio do diálogo das idéias, informações e cooperação entre seus pares. O precursor dessa abordagem no Brasil foi o professor Paulo Freire, que vê como objetivo fundamental deste paradigma educacional a busca da transformação social. A realidade não pode ser simplesmente observada com passividade, ela exige uma intervenção responsável para construir uma sociedade mais justa e igualitária. Para FREIRE (2001) a substantividade de suas idéias parte essencialmente do respeito ao outro, mas acrescenta outras: 
Outra substantividade de minhas idéias é minha compreensão da história como possibilidade, minha rejeição de qualquer compreensão fatalista ou visão determinista da história. Outro aspecto de minha substantividade é meu amor incondicional pela liberdade e minha certeza de que podemos nos tornar seres dialógicos, que podemos também nos tornar seres com capacidade para tomar decisões e que podemos também desenvolver a capacidade para a ruptura. Logo, por isso combato e luto contra qualquer sistema -social, econômico, político-, que me proíba de ser, de perguntar, de discutir, de intervir, de ser um ser humano decente (p.79-80).

Na relação do conhecer-se, SANTOS (2000) nos alerta para a seguinte reflexão: "a maioria das pessoas são subjetivas a respeito de si próprias e objetivas - algumas vezes, terrivelmente objetivas - a respeito dos outros. O importante é ser-se objetivo em relação a si próprio e subjetivo em relação aos outros" (p. 17). Ao reconhecermos esta dificuldade dá-se o início da sua superação. Neste contexto, o essencial é iniciar o processo a partir da autoreflexão enquanto pessoa e profissional.

\section{OParadigma Emergente ea docência universitária}

O Paradigma Emergente inclui um momento de reflexão sobre a prática pedagógica, principalmente, nas instituições de ensino superior. Para que se supere a reprodução do conhecimento, os educadores serão levados a investigar novas metodologias de ensino que busquem a qualidade diante desta visão sistêmica de mundo.

DEMO (1992) indica que o marco norteador na construção de métodos criativos no trabalho docente seja proposto a partir da visão de que o aluno precisa "aprender a aprender". Esta proposição é bastante expressiva na contribuição de DEMO (1992) que alerta:

O que marcaria a modernidade educativa seria a didática do aprender a aprender, ou do saber pensar, englobando, num todo só, a necessidade de apropriação do conhecimento disponível e seu manejo criativo e crítico. A primeira necessidade é da ordem dos insumos instrumentais, enquanto a segunda perfaz mais propriamente o desafio humano da qualidade. A competência que a escola deve consolidar e sempre renovar é aquela fundada na propriedade do conhecimento como instrumento eficaz da emancipação das pessoas e da sociedade. Neste contexto, mera transmissão é pouco, embora como insumo seja indispensável. Em termos emancipatórios, competência jamais coincidirá com cópia, reprodução, imitação. Torna-se essencial construir uma atitude positiva construtiva, crítica e criativa, típica do aprender a aprender (p. 25). 
Neste momento, onde a sociedade da informação influencia fortemente nossas vidas, busca-se a superação da utilização só do quadro de giz que, normalmente, apenas focaliza processos que levam à reprodução do conhecimento. Hoje os docentes são desafiados a buscar práticas pedagógicas que utilizem recursos tecnológicos como: televisão, vídeo, computador, CDROM e a Internet. Estes são instrumentos que auxiliam na pesquisa e, conseqüentemente, na produção do conhecimento. O desafio está centrado na utilização da tecnologia a favor da aprendizagem significativa, no sentido de levar o aluno a acessar as informações, interpretar e produzir novas informações, sendo crítico, criativo e ético.

\section{Oprofessor profissionalno Paradigma Emergente}

O professor vem recebendo da sociedade, nas últimas décadas, especialmente pelos meios de comunicação jornalística e televisada, tratamento como se fosse um profissional de qualidade questionável. Sem a intenção de generalizar e nem de concordar com esta afirmação, não se pode negar a desvalorização profissional progressiva que atinge o professor também como pessoa.

A formação dos professores mais críticos e reflexivos pode ajudar a reverter essa visão pessimista que tem acompanhado os docentes na sociedade. Esse profissional pode retomar seu lugar no momento que passar a desenvolver sua competência intelectual, técnica e política. Torna-se necessário que a categoria profissional se una e reivindique seus direitos, para que, assim, retome a auto-estima e o reconhecimento da sociedade sobre o real valor do professor.

As reflexões sobre a atuação do professor não se restringem apenas à alteração de sua metodologia de ensino ou seu fazer didático, mas também ao seu posicionamento filosófico, epistemológico, político e ideológico. 0 docente precisa entender-se como ser histórico e deve questionar-se sobre suas intencionalidades (PIMENTEL, 1993).

O professor precisa assumir novos desafios, além de apenas fornecer informações aos seus alunos. É preciso ser capaz de organizar situações de aprendizagem. SCHÖN (1992) afirma que o conhecimento do professor como profissional forma-se a partir da experiência vivenciada e da reflexão dentro da sua ação docente.

A mudança do professor enquanto profissional não se restringe ao desenvolvimento de um conjunto de competências docentes, mas também de uma revisão enquanto pessoa e cidadão que atua no universo. O professor está envolvido num processo de constante relação com todos os seres e em intermitente evolução. Neste contexto, cabe a contribuição de VASCONCELLOS 
(1996, p. 10) que propõe para o professor a reunião de três capacidades igualmente desenvolvidas. São elas:

- a capacidade de transmitir conhecimento;

- a capacidade de criticar as relações socioculturais da sociedade em que está inserido, assim como o momento histórico-político no qual vive;

- e a de investigador que seja capaz de produzir novos conhecimentos através de pesquisas, de estudos sistemáticos e de investigações empíricas.

Estas capacidades devem ser exercidas com reflexividade (PERRENOUD , 2001), pois concentram-se como fonte de uma ação mais controlada e de uma integração de diferentes tipos de saberes. É de suma importância o professor aprender a refletir sobre a sua prática principalmente no momento da ação docente.

A concepção integrada do mundo trará benefícios no momento em que superamos a visão do ser humano como um mero produto de mercado. O indivíduo deverá tornar-se responsável por si mesmo e pelo outro. O benefício desta nova visão será o de compreender a sociedade como um todo na qual os cidadãos necessitam de uma qualidade digna de vida. Neste contexto, a própria utilização das tecnologias disponíveis precisa ser feita de forma ética, crítica, criativa e que conduza ao bem-estar do homem na sociedade.

Nesta visão, a prática pedagógica inovadora busca resgatar o verdadeiro compromisso da escola com e para a sociedade. Os professores, principalmente os que atuam na educação superior, são conclamados e encorajados a rever suas práticas, criando um programa que busque a aprendizagem, pois conforme BEHRENS (2001, p.90) a mudança do foco do ensino para aprendizagem permite que as disciplinas passem a se denominar como programas de aprendizagem. Essa proposição passa a exigir que os programas de aprendizagem sejam elaborados e discutidos coletivamente pelos professores, para que todos possam conhecer os programas propostos pelo conjunto dos docentes para aquele período. Com essa atitude educativa, é possível que o professor passe a ter uma visão de totalidade, de interconexão e da necessidade de articulação entre os diferentes períodos que compõem um curso. Neste processo, BEHRENS e AGE (2001, p.93) defendem que, aliado ao programa de aprendizagem, o professor proponha também um contrato didático, que poderia ser entendido como "uma técnica estruturada e organizada nas atividades do aluno, no qual o professor entra em acordo com os mesmos sobre os conteúdos a serem estudados, o método de trabalho a ser realizado e a proposta transparente do processo de avaliação". Esse processo exige do professor o diálogo com seus pares, com os alunos e, sobretudo, a aplicação dos pressupostos que caracterizam o paradigma emergente em sala de aula e fora dela. 
O conhecimento, sob todos os aspectos, deve ser diligenciado, principalmente porque ele se refere à própria visão de mundo do professor e do aluno. Esta produção do conhecimento é vital para que possamos analisar, interpretar e transformar os problemas que norteiam o próprio mundo. MORIN (2000, p. 35) alerta para uma grande questão do novo milênio: "como ter acesso às informações sobre o mundo e como ter a possibilidade de articulálas e organizá-las?". Esta questão nos leva a refletir que para organizar os conhecimentos é necessária a transformação do pensamento, e isto é uma questão fundamentalmente da Educação.

A investigação sobre as informações e como revertê-las em conhecimento contextualizado, globalizado, multidimensional e complexo são características que fazem parte das recomendações pedagógicas para a Educação do século XXI. As informações adquiridas precisam ser situadas dentro do contexto histórico e à produção do conhecimento advem da articulação das diversas partes que compõem o todo. $\mathrm{O}$ ser humano e a sociedade têm 0 conhecimento como unidades complexas, que precisa envolver variadas dimensões como: pedagógica, biológica, psíquica, social, afetiva, entre outras. $\mathrm{O}$ conhecimento tem o caráter multidimensional, ou seja, não se poderia isolar uma dimensão da outra e muito menos do todo. A complexidade também faz parte do conhecimento, pois ela é a união entre a unidade e a multiplicidade. Portanto, cabe à Educação atual lidar com as informações, os fatos ou os dados não mais de forma isolada ou fragmentada. Ela deve promover a integração do cidadão consigo mesmo, com a sociedade e com o ambiente em que vive.

O Ensino Superior entra no novo milênio promovendo profundas mudanças em sua forma de atuar, ou seja, no processo pedagógico já não cabem mais ações que se restrinjam ao "escute, leia, decore e repita" (BEHRENS, 1999, p. 62). Esta nova visão metodológica recai sob dois aspectos importantíssimos: a competência técnica e o sentido político da prática pedagógica.

A reflexão e análise oportuna de GUTIÉRREZ (1999) levam a repensar sobre o processo pedagógico enquanto um caminho a ser trilhado, conjugando a aprendizagem com as experiências de vida. Esta ação desafiadora propõe inovação, porém, só será concretizada na medida em que: "encontremos sentido para caminhar para a aprendizagem cotidiana; orientemos pedagogicamente as tendências e indicadores inerentes à colocação em marcha da cidadania ambiental; e apoiemos nosso caminhar nas ferramentas conceituais e nos instrumentos e estratégias conforme essa nova realidade. (GUTIÉRREZ, 1999, p. 62).

Mas para que se abram novos caminhos, é importante trazer o significado de que devemos "dar sentido ao que fazemos, compartilhar sentidos, impregnar de sentido as práticas da vida cotidiana e compreender o semsentido (non-sense) de muitas outras práticas que aberta ou sorrateiramente 
tentam se impor" (GUTIÉRREZ, 1999, p. 63). Além de trilhar um caminho, fazendo-o com sentido, a trajetória deverá ser feita com atitude de aprendizagem para a vida. A participação de todos neste processo é fundamental para 0 bom êxito desta caminhada. GUTIÉRREZ (1999) resume a atitude de aprendizagem caracterizando uma sociedade "pela abertura, dinamismo, interatividade e complexidade, que requer processos pedagógicos igualmente abertos, dinâmicos e criativos, nos quais os protagonistas - como sujeitos do processo estejam em atitude de aprendizagem permanente e, portanto, participem, se expressem e se relacionem tal qual se concebe na mediação pedagógica" ( $p$. $64)$.

Nesse contexto não poderá faltar o diálogo entre os profissionais envolvidos com o fazer educativo, pois a interlocução é a "essência desse ato". O autor enfatiza, ainda, o significado de interlocução dizendo que é "encontro, diálogo horizontal, ter sempre presente o outro como legítimo outro, porque partimos de suas experiências, crenças, sonhos, desejos... Assim, interlocução implica respeito, tolerância e reconhecimento das idéias e contribuições do outro, como já dissemos e agora repetimos, implica interação, comunicação, comunhão, amor" (1999, p.66).

O processo de aprender, portanto, deve tornar-se produtivo e proporcionar resultados visíveis e duradouros, especialmente os advindos da própria prática. Educadores e educandos constroem juntos os conhecimentos e os expressam na medida em que o processo pedagógico, utilizado para esta construção, se envolva com situações que retratem o real. Com referência a estes processos vivenciados na realidade, GUTIÉRREZ (1999) observa a importância da produção do conhecimento propondo que "da mesma forma como o artista revela prazer em sua obra, assim o interlocutor revela ter prazer em sua criação produtiva: tem diante de si os filhos de seu esforço e experiência, de sua invenção, de sua capacidade de indagar e de observar, da significação que faz de sua realidade" (p. 69).

Quando os educandos forem "donos de suas próprias expressões", caminharem com seus "próprios pés", e estiverem "passando de receptores para criadores de informações, e agentes da mudança", o processo de aprendizagem será significativo (GUTIÉRREZ, 1999, p. 71).

A prática pedagógica tem como termômetro os procedimentos de avaliação contínua durante a caminhada. De nada adiantaria restringirmos a avaliação ao final do processo, pois o levantamento dos acertos e possíveis erros, ao término de uma jornada, não permitem reestruturar as atividades didáticas propostas durante o processo. A avaliação não deve ser um momento de fiscalização ou de controle. Ao contrário, ela deve reportar-se aos objetivos e aos processos metodológicos e avaliativos atendendo ao paradigma emergente selecionado desde 0 início do processo. A avaliação, acima de tudo, deve ter sentido para quem está aprendendo. 
Aprender é muito mais do que "captar" informações desprovidas de contexto. VEIGA (1993) contribui propondo que é preciso "trabalhar o processo de ensino a partir da análise e compreensão das condições, interesses e necessidades da sociedade e da educação. Portanto, o ensino não pode ser entendido isolado do contexto mais amplo que o engloba" (p. 84).

\section{As perspectivas docentes no século XXI}

A formação do professor, segundo NÓVOA (1992), subdivide-se em dois paradigmas perdidos: o do professor como pessoa e o do professor como profissional. O primeiro leva em conta o desenvolvimento pessoal. Um aspecto que vem sendo resgatado na educação é o da experiência. Procura-se a recuperação da prática pedagógica na capacidade de reflexão crítica, apoiando-se nas experiências vivenciadas e nas histórias de vida dos professores. A busca da melhoria na formação profissional precisa contemplar processos de união entre corpo docente e administrativo da escola. Esses processos podem ser oferecidos quando os gestores preocupam-se com a formação continuada dos professores. A formação não se faz antes da mudança, mas durante a construção de caminhos de inovação.

A instalação do diálogo entre professores, gestores e alunos leva a ampliação de três dimensões na capacitação docente: "conhecimento na ação, reflexão na ação e reflexão sobre a ação e sobre a reflexão da ação" (SCHON,1992). Nesta perspectiva restabelece-se o caminho pessoal e profissional do professor, dando voz ao docente, ouvindo seus anseios, respeitando seu discurso e o poder de reflexão sobre ele, sua prática e seu papel na sociedade. A dinâmica que se impõe é propor o trabalho coletivo, a união entre pares, que levem os professores a uma situação de investigação de suas próprias práticas, agregando os processos de pensar e o de fazer.

A formação mútua e colegiada instiga a construção do papel do professor como formador e formado, a partir das relações dialógicas que permitam ao docente ser reflexivo sobre sua própria prática e a de seus pares. Neste contexto, cabe a contribuição de NÓVOA (1992) quando alerta que: "As escolas dedicam muito pouca atenção ao trabalho de pensar o trabalho, isto é, as tarefas de concepção, análise, inovação, controle e adaptação (p. 22)”. A identidade do professor como profissional precisa ser construída dentro do espaço da escola, para depois projetá-la na sociedade.

As mudanças necessitam ainda do envolvimento dos docentes, segundo NÓVOA (1992), em diferentes níveis na formação permanente:

- Formação docente universitária: a comunidade acadêmica universitária precisa superar a formação completamente distanciada da realidade. A universidade apresenta a receita para o doente sem nunca tê-lo visitado, 
portanto, os processos que envolvam a formação de professores precisam partir das situações criadas e das exigências levantadas por eles mesmos. 0 compromisso é gerar formação de profissionais envolvidos com a práxis.

- Formação inicial de docentes: o professor é levado a improvisar na sala de aula e isto o compromete substancialmente como profissional. Torna-se urgente a criação de espaços para reflexão compartilhada, traçando projetos de capacitação permanente e intermitentemente, subsidiados por uma rede de informação atualizada.

- Formação continuada: a capacitação precisa superar propostas elaboradas por especialistas que estão fora do contexto escolar. Os projetos que envolvam formação contínua precisam atender aos anseios dos professores e suas reais necessidades.

\section{Osalto dequalidadena formação docentedos mestrandos}

A formação continuada dos docentes no decorrer do Mestrado em Educação ou em outros segmentos que ofereçam espaços para discussão dialógicas de suas práticas educativas passa por atitudes que levem a superar o "individualismo pedagógico" e demanda processos de reflexão e de trabalho coletivo.

A formação continuada precisa ser aliada à criação coletiva de um estatuto profissional produzido pelos professores. Esse estatuto auxiliaria no entrosamento e envolvimento dos docentes na construção positiva de uma nova imagem na sociedade. Acreditamos que o processo de mudança se estrutura a partir da vontade política do professor e das políticas públicas. Portanto, o desafio imposto na formação pedagógica do docente universitário envolve a criação de situações que permitam dialogar e construir uma ação docente crítica e reflexiva.

O processo transformador que envolveu os mestrandos em educação da PUCPR na disciplina de Paradigmas Contemporâneos na Educação Superior permitiu levantar, dialogar, discutir e buscar possíveis caminhos para construir uma ação docente. A partir dos depoimentos dos professores-mestrandos acredita-se que essa caminhada tenha proporcionado reflexões que se concretizarão em uma prática pedagógica emergente preocupada com a qualificação profissional e com a transformação da sociedade como um todo.

\section{Referências}

BEHRENS, M. A. O Paradigma Emergente e a Prática Pedagógica. Curitiba: Champagnat, 1999. 
. Formação continuada dos professores e a prática pedagógica. Curitiba: Champagnat, 1996.

. Projetos de aprendizagem colaborativa num paradigma emergente IN: MORAN, J. M.; MASETTO, M. T., BEHRENS, M. A. Novas tecnologias e mediação pedagógica. Campinas: Papirus, 2000.

\& AGE , E. M. J. Aprendizagem por projetos e os contratos didáticos. v. 2,n.3,jan/jun. In: Revista Diálogo Educacional. Curitiba: Champagnat, 2001. BRANDÃO, D. M.S. \& CREMA, R. O novo paradigma holístico: ciência, filosofia, arte e mística. 2. ed. São Paulo: Summus, 1991.

CAPRA, F. A teia da vida. Uma nova compreensão científica dos sistemas vivos. São Paulo: Cultrix, 1996.

CARDOSO, C. M. A canção da inteireza. Uma visão holística da educação. São Paulo: Summus, 1995.

DEMO, Pedro. Desafios modernos da educação. Petrópolis: Vozes, 1992.

FREIRE, P.; FREIRE, A. M. (Org.). Pedagogia dos Sonhos Possíveis. São Paulo:UNESP, 2001.

GATE (Global Alliance for Transforming Education). Educação 2000. Uma perspectiva holística. Dezembro. www.globalalliance.com.br.Tradução de Rita de Cássia Santos Vanin. Mestranda em Educação da PUCPR, 1991.

GUTIÉRREZ, F. Ecopedagogia e Cidadania Planetária. São Paulo: 1999.

KHUN, T. A estrutura das revoluções científicas. 5. ed. São Paulo: Perspectiva, 1998.

LASZLO, E. Conexão Cósmica: Guia pessoal para a emergente visão da ciência. Rio de Janeiro: Vozes, 1999.

MIZUKAMI, M. G. N. Ensino: as abordagens do processo. São Paulo: Editora Pedagógica e Universitária, 1986.

MORAES, M.C. O paradigma educacional emergente. Campinas: Papirus, 1997.

MORIN, E. Os sete saberes necessários à Educação do futuro. São Paulo: Cortez, 2000.

A religação dos saberes. O desafio do século XXI. Rio de Janeiro: Bertrand Brasil, 2001. 
PIMENTEL, M. da G. O professor em construção. Campinas: Papirus,1993. PERRENOUD, P. Dez novas competências para ensinar: convite à viagem. 2. ed. Porto Alegre: Artmed, 2001.

SANTOS, B. de S. A crítica da razão indolente: contra o desperdício da experiência. São Paulo: Cortez, 2000.

SCHÖN, D. Formar professores como profissionais reflexivos. In: NÓVOA, A. Os professores e sua formação. Lisboa: Dom Quixote, 1992.

VASCONCELLOS, C. S. A construção do conhecimento em sala de aula. São Paulo: Libertad, 1996.

VEIGA, I. P. A. A construção da didática numa perspectiva histórico-crítica da educação: uma introdução. In: OLIVEIRA, M. R. S.N. (Org.). Didática: Ruptura, compromisso e pesquisa. Campinas: Papirus, 1993.

WEIL, P. O novo Paradigma Holístico. Ondas à procura do mar. In: BRANDÃO, D.; CREMA, R. 0 novo paradigma holístico. Ciência, filosofia, artes e mística. São Paulo: Summus, 1991. 